\title{
The relationship between plasma concentration of metoprolol and CYP2D6 genotype in patients with ischemic heart disease
}

\author{
Anna Wojtczak ${ }^{\text {a,*, Maciej Wojtczak }}{ }^{\text {b }}$, Jadwiga Skrętkowicz ${ }^{a}$ \\ ${ }^{a}$ Department of Pharmacogenetics, Medical University of Lodz, Łódź, Poland \\ ${ }^{\mathrm{b}}$ Institute of Chemical Technology of Food, Lodz University of Technology, tódź, Poland
}

\section{A R T I C L E I N F O}

\section{Article history:}

Received 1 October 2013

Received in revised form 29 November 2013

Accepted 16 December 2013

Available online 3 April 2014

\section{Keywords:}

CYP2D6 genotype

Metoprolol

\begin{abstract}
A B S T R A C T
Background: Metoprolol is the one of the most commonly used $\beta$-blockers in the treatment of ischemic heart disease and it is extensively metabolized in the liver undergoing oxidation by CYP2D6 isoenzyme of cytochrome P450. Gene encoding the CYP2D6 enzyme is characterized by genetic polymorphism. The CYP2D6 oxidation polymorphism has a major impact on the effectiveness and safety of the treatment. The aim of the study was to evaluate the relationship between plasma concentration of metoprolol and the CYP2D6 genotype in patients with ischemic heart disease.

Methods: Fifty patients were interviewed and subsequently enrolled into the study. The patients received metoprolol twice daily at a dose of $50 \mathrm{mg}$. The blood samples were analyzed for two major defective alleles for CYP2D6 - CYP2D6*4 and CYP2D6*3 - by the polymerase chain reaction-restriction fragment length polymorphism (PCR-RFLP) method. Metoprolol concentration in plasma was determined by using the new and unique high-performance liquid chromatography (HPLC) method in the author's own modification with Corona CAD detector (Charged Aerosol Detection).

Results: In the test group, genotypes conditioning poor oxidation (PM) occurred in 3 patients (6\%), while 47 patients (94\%) had genotypes coding for extensive metabolism (EM). Patients with PM genotypes had significantly higher plasma concentrations of metoprolol than the patients with EM genotype (mean $92.25 \pm \mathrm{SD} 36.78 \mathrm{ng} / \mathrm{ml}$ vs. mean $168.22 \pm \mathrm{SD} 5.61 \mathrm{ng} / \mathrm{ml}$, respectively). Established relationships were statistically significant (NIR test, $p=0.0009$ ).

Conclusions: This study demonstrated that the CYP2D6 genotype remains a major determinant of the metoprolol plasma concentrations. The pharmacogenetic effect is likely to have consequences on both, the clinical benefit of metoprolol treatment and adverse drug reactions. The use of Corona CAD detector seems to be a very good alternative method for the determination of metoprolol concentration in plasma. (C) 2014 Institute of Pharmacology, Polish Academy of Sciences. Published by Elsevier Urban \& Partner Sp.
\end{abstract} z o.o. All rights reserved.

\section{Introduction}

$\beta$-Adrenoreceptor antagonists ( $\beta$-blockers) have been drugs of first choice in patients with stable coronary artery disease who have no contraindications to their use. These drugs cause the reduction in heart rate and myocardial contractility, thereby the demand of myocardium for oxygen is decreasing. $\beta$-Blockers by prolongation of diastole phase increase blood flow through the coronary arteries and perfusion in myocardium. The measurable effects of the $\beta$-blockers treatment are: improvement of exercise tolerance and reduction in the intensity and frequency of coronary pain. $\beta$-Adrenoreceptor

\footnotetext{
* Corresponding author.

E-mail address: anna.wojtczak@umed.lodz.pl (A. Wojtczak).
}

antagonists are effective in reducing morbidity and mortality in patients with ischemic heart disease [1].

The currently used $\beta$-blockers differ in their selectivity for $\beta_{1}$ and $\beta_{2}$-adrenergic receptors, lipophilicity and route of elimination. Metoprolol is one of the most commonly used $\beta$-blockers in the treatment of ischemic heart disease. Metoprolol is a lipophilic $\beta_{1}$ selective blocker. This drug is well absorbed from the gastrointestinal tract and undergoes extensive distribution in body tissues; it also passes through the blood-brain barrier. The highest plasma concentration value of metoprolol is reached approximately $2 \mathrm{~h}$ after administration of a single dose. Metoprolol is extensively metabolized (oxidation) in the liver by the CYP2D6 isoenzyme of cytochrome P450 [2].

The gene encoding the CYP2D6 enzyme is highly polymorphic. The CYP2D6 oxidation polymorphism has a major impact on the 
efficiency and safety of the treatment. The changes in drug metabolism due to genetic factors can cause side effects or reduce the therapeutic effects. Data obtained from the meta-analysis of large groups of patients suggest that more than $40 \%$ of adverse events were noted due to lack of dose modification based on the genotype of the patient $[3,4]$.

The CYP2D6 activity ranges considerably within a population and includes mainly extensive metabolizers (EMs) and poor metabolizers (PMs). There is a considerable variability in the CYP2D6 allele distribution among different ethnic groups, resulting in variable percentages of PMs and EMs in a given population. The prevalence of CYP2D6 poor metabolizers is approximately 6$10 \%$ in Caucasian populations. Many allelic variants and a series of subvariants of the CYP2D6 gene have been reported and the number of alleles is still growing. Among these are fully functional alleles, alleles with reduced function and null (non-functional) alleles, which convey a wide range of enzyme activity, from no activity to ultrarapid metabolism of substrates. As a consequence, drug adverse effects or lack of drug effect may occur if standard doses are applied. The alleles ${ }^{*} 10(100 \mathrm{C}>\mathrm{T}),{ }^{*} 17(1023 \mathrm{C}>\mathrm{T})$, and ${ }^{*} 41(2988 \mathrm{G}>\mathrm{A})$ give rise to substrate-dependent decreased activity. Null alleles of CYP2D6 do not encode a functional protein and there is no detectable residual enzymatic activity. It is clear that alleles *3 (2637delA), *4 (1934G > A), ${ }^{*} 5$ (CYP2D6 deleted), *6 (1707delT), ${ }^{*} 7(2935 \mathrm{~A}>\mathrm{C}),{ }^{*} 8(1758 \mathrm{G}>\mathrm{T}),{ }^{*} 11(883 \mathrm{G}>\mathrm{C}),{ }^{*} 12$ (124G > A), ${ }^{*} 14(1758 \mathrm{G}>\mathrm{A}),{ }^{*} 44(2950 \mathrm{G}>\mathrm{C}),{ }^{*} 56(3201 \mathrm{C}>\mathrm{T})$ and ${ }^{*} 62(4044 \mathrm{C}>\mathrm{T})$ have no enzyme activity. They are responsible for the PM phenotype when present in homozygous or compound heterozygous constellations. These alleles are of clinical significance as they often cause altered drug clearance and drug response. Among the most important variants are CYP2D6 * $3,{ }^{*} 4$, ${ }^{*} 5,{ }^{*} 10,{ }^{*} 17$ and ${ }^{*} 41[5-7]$.

The aim of the present study was to evaluate the relationship between plasma concentration of metoprolol and the CYP2D6 genotype in patients with ischemic heart disease by means of a new and unique HPLC method with Corona CAD detector.

\section{Materials and methods}

Fifty patients ( 38 women and 12 men) were interviewed and subsequently enrolled into the study. The age of the patients ranged from 39 to 81 years (mean $63.5 \pm 16.3$ ) and was similar for both sexes. The patients received metoprolol twice a day at a dose of $50 \mathrm{mg}$.

The protocols for the study were reviewed and approved by the Ethics Committee on Human Research at Medical University of Lodz. Each subject agreed to sign a written informed consent.

\section{Examination of genotype oxidation}

The blood samples were analyzed for two major defective alleles for the CYP2D6 gene - CYP2D6*4 and CYP2D6*3 - by the polymerase chain reaction-restriction fragment length polymorphism (PCR-RFLP) method according to the procedure proposed by Smith et al. [8]. DNA was arranged from leukocytes extracted from peripheral blood. PCR amplification was conducted in a Mastercycler Personal thermal cycler (Eppendorf, Germany). The obtained product of amplification was subjected to digestion by restriction enzymes. The restriction endonucleases BstN 1 (New England BioLabs, USA) (CYP2D6*4) and HpaII (Invitrogen USA) (CYP2D6*3) were used to detect the presence or absence of mutations at position G1934A and A2637del, respectively. Separation of the obtained digestion products was conducted using electrophoresis in $2 \%$ agarose gel. The obtained bands were analyzed in UV light.

\section{Determination of the metoprolol concentration}

The metoprolol concentration in plasma was determined by using the HPLC method in the author's own modification with UV DAD and Corona CAD detectors (Charged Aerosol Detection). CAD is a new and unique technique in which the eluent after passing through the HPLC column is dissipated in the original stream of nitrogen to remove the mobile phase.

In order to determine plasma concentrations of metoprolol in the patients, samples of peripheral venous blood were taken at the time of expected maximum concentrations ( $2-3 \mathrm{~h}$ after the last dose) at steady state. Immediately after collecting, the blood samples were centrifuged to obtain plasma. After thawing, the samples were subjected to extraction using the method of SPE (solid phase extraction) on the Strata-X-C $33 \mu \mathrm{m}$ columns (Phenomenex).

Chromatographic separation of compounds was made at temperature of $25^{\circ} \mathrm{C}$ on a Hypersil GOLD column $(150 \mathrm{~mm} \times 4.6 \mathrm{~mm}, 5 \mathrm{~mm})$ with a pre-column $(4 \mathrm{~mm} \times 3 \mathrm{~mm}$, $5 \mathrm{~mm}$ ). The mobile phase flow was $1 \mathrm{ml} / \mathrm{min}$. Corona CAD detection was carried out at $20 \mathrm{pA}$ and a pressure of nitrogen 2.4 bar. UV detection was performed at a wavelength of 220 and $270 \mathrm{~nm}$.

The linearity was demonstrated over the range $10-200 \mathrm{ng} / \mathrm{ml}$; the coefficient of correlation $(r)$ was 0.9991 . The limit of quantification ( $L O Q$ ) obtained during the validation was $10 \mathrm{ng} /$ $\mathrm{ml}$. The precision of the method was expressed as relative standard deviation for repeatability $\left(R S D_{r}\right)$ at $20 \%$. Evaluation of the method accuracy was determined on the basis of the recovery value of metoprolol standard fortified samples. The analysis obtained $93 \%$ recovery. The concentration of metoprolol in plasma was calculated using metoprolol standard and atenolol as an internal standard (Sigma-Aldrich, Europe). The Chromeleon v.6.70 software was used for registration and integration of data.

\section{Statistical analysis}

The results were statistically analyzed. The age of the patients was characterized by giving the size of the group, the arithmetic mean and standard deviation. The relationship between the CYP2D6 genotype and the concentrations of metoprolol was calculated using the NIR test. A $p$-value less than 0.05 was considered to be statistically significant. All statistical calculations were made using the statistical program STATISTICA 10 (StatSoft, Inc.).

\section{Results}

Determination of metoprolol concentration in plasma was performed in 50 patients with ischemic heart disease, including 38 women (76.0\%) and 12 men (24.0\%).

Among the subjects the CYP2D6*1,CYP2D6*3 and CYP2D6*4 alleles were identified using the PCR-RFLP method. It allowed the

Table 1

The relationship between CYP2D6 genotype and concentrations of metoprolol in the serum of the patients with ischemic heart disease.

\begin{tabular}{lccc}
\hline Genotype & $n(\%)$ & $\begin{array}{l}\text { Metoprolol } \\
{[\mathrm{ng} / \mathrm{ml}]} \\
\text { mean } \pm \text { SD }\end{array}$ & $\begin{array}{l}\text { Metoprolol } \\
{[\mathrm{ng} / \mathrm{ml}]} \\
\text { range }\end{array}$ \\
\hline CYP2D6*1/*1 & $32(64 \%)$ & $85.71 \pm 36.64$ & $10.68-143.55$ \\
CYP2D6* $1{ }^{*} 4$ & $13(26 \%)$ & $99.07 \pm 30.64$ & $58.04-157.27$ \\
CYP2D6*1/*3 & $2(4 \%)$ & $152.65 \pm 8.73$ & $146.48-158.83$ \\
All EM & $47(94 \%)$ & $92.25 \pm 36.78$ & $10.68-158.83$ \\
CYP2D6* $4{ }^{*} 4$ & $1(2 \%)$ & 165.36 & - \\
CYP2D6*3/*4 & $1(2 \%)$ & 164.61 & - \\
CYP2D6*3/3 & $1(2 \%)$ & 174.69 & - \\
All PM & $3(6 \%)$ & $168.22 \pm 5.61$ & $164.61-174.69$ \\
\hline
\end{tabular}

PM - poor metabolizers; EM - extensive metabolizers; Test NIR $p=0.0009$. 


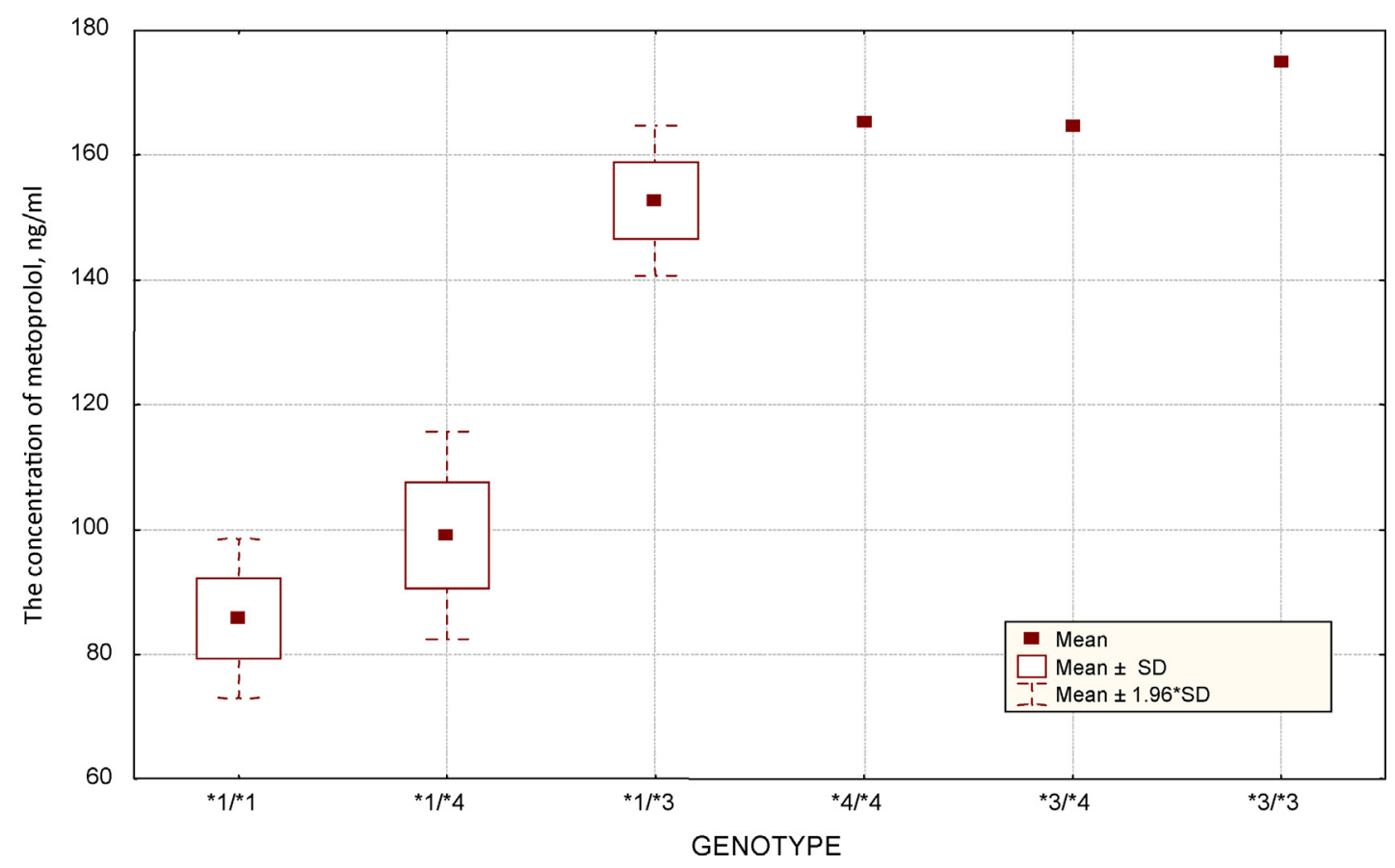

Fig. 1. The relationship between plasma concentration of metoprolol and CYP2D6 genotype in patients with ischemic heart disease.

separation of two groups of metabolizers: the poor metabolisers (PMs) - homo- or heterozygotes with two nonfunctional alleles and the extensive metabolisers (EMs) - wild homozygotes or heterozygotes with a wild and a nonfunctional allele.

Only three patients (6\%) were PMs with two nonfunctional alleles. Other subjects presented EM genotypes. The distribution of CYP2D6 genotypes is shown in Table 1.

Mean plasma concentrations of metoprolol in the patients was $96.81 \pm \mathrm{SD} 40.04 \mathrm{ng} / \mathrm{ml}$ and fell within the therapeutic drug concentrations. The correlations between plasma concentration of metoprolol and the CYP2D6 genotype of patients with ischemic heart disease are presented in Table 1 and Fig. 1. As the data show, the patients with PM genotypes exhibited significantly higher plasma concentrations of metoprolol than EMs. The established correlations were statistically significant (NIR test, $p=0.0009$ ).

\section{Discussion}

$\beta$-Adrenergic receptor antagonists are one of the most widely used medicaments in the treatment of diseases of the cardiovascular system. The polymorphism of gene encoding the CYP2D6 enzyme which is responsible for the metabolism of the $\beta$-blockers can affect the efficiency of pharmacological treatment. The changes in enzyme activity caused by the CYP2D6 gene polymorphism may affect the pharmacokinetics, biotransformation, and of course drug concentration. Zhou and Wood showed that the clearance of the carvedilol R-enantiomer (+) was $66 \%$ lower among poor metabolizers compared to EMs. The researchers also demonstrated that in PMs the area under the curve (AUC) increased by $138 \%$ [9].

Metoprolol is a lipophilic selective $\beta_{1}$-adrenergic receptor antagonist and one of the major substrates for CYP2D6. In studies, much attention was paid to pharmacogenetic polymorphism of the CYP2D6 gene and its important impact on the pharmacokinetics and pharmacodynamics of metoprolol [10]. Koytchev et al. investigated the influence of the CYP2D6*4 allele on the pharmacokinetics of metoprolol. The results of this trial demonstrated a good correlation between the CYP2D6 genotype and plasma concentration of metoprolol. The study showed also a significant correlation between the decrease in heart rate and the concentrations of metoprolol [11]. Taguchi et al. evaluated the effect of polymorphic alleles (CYP2D6*2, CYP2D6*10, CYP2C19*2 and CYP2C19*3), age, sex, and heart failure on the pharmacokinetic parameters of metoprolol. The $\mathrm{CL} / \mathrm{F}$ value in patients homozygous for the CYP2D6* 10 allele was $64 \%$ lower than that in patients with the CYP $2 D 6^{*} 1 /{ }^{*} 1$ or ${ }^{*} 1 /{ }^{*} 2$ genotype [12]. Nozawa et al. showed, that in patients routinely treated with metoprolol, the CYP2D6 genotype significantly affects circadian variations of beta-adrenergic inhibition induced by metoprolol [13].

In the present study, we investigated the effect of the CYP2D6 gene polymorphism on the concentration of metoprolol in patients with ischemic heart disease. Several investigations demonstrated that the CYP2D6 genotype remains a major determinant of metoprolol plasma concentrations during therapy. Mean plasma concentrations of metoprolol in our patients was $96.81 \pm \mathrm{SD}$ $40.04 \mathrm{ng} / \mathrm{ml}$ and fell within the therapeutic drug concentrations. Poor metabolizers exhibited markedly higher (1.8-fold) plasma concentrations of metoprolol as compared to extensive metabolizers $(168.22 \pm 5.61 \mathrm{ng} / \mathrm{ml}$ vs. $92.25 \pm 36.78 \mathrm{ng} / \mathrm{ml})$. Established correlations were statistically significant (NIR test $p=0.0009$ ). Our results corresponded with a recently published systematic review and metaanalysis by Blake et al. [14]. Pooled analysis $(n=264)$ demonstrated differences in peak plasma metoprolol concentration, area under the concentration-time curve, elimination half-life, and apparent oral clearance that were 2.3-, 4.9-, 2.3-, and 5.9-fold lower between extensive and poor metabolizers, respectively, and 5.3-, 13-, 2.6-, and 15-fold lower between ultrarapid and poor metabolizers (all $p<0.001$ ), respectively. Also Rau et al. showed that the impact of the CYP2D6 genotype on metoprolol plasma concentration persists during long-term treatment. PMs had a 6-fold higher steady-state concentration of metoprolol [2].

In our patients, among homozygotes with two wild alleles, the concentration of metoprolol is in a wide range: from 10.68 to $143.55 \mathrm{ng} / \mathrm{ml}$. This observation may explain the presence of more than two CYP2D6 gene copies. The multiplication of gene can contribute to ultrarapid metabolism and thus to low concentrations of the drug. However, in our study, subjects were not assessed for the presence of gene duplication. 
The results of the presented study indicated higher concentrations of metoprolol among the CYP2D $\left.6^{*} 1\right|^{*} 3$ heterozygotes with one nonfunctional allele (EMs). Similar findings were reported by Sharp et al. In their research the median concentrations were 3.2fold higher in subjects with one functional allele compared with subjects with two functional alleles [15].

On the basis of the considerable impact of the CYP2D6 polymorphism on the disposition of substrates, it has often been suggested that PMs are more susceptible to adverse effects of the drugs than EMs. Lennard et al. showed longer halflife of metoprolol in poor metabolizers $(7.5 \mathrm{~h}$ ) than in extensive metabolizers $(2.8 \mathrm{~h})$. Associated with drug activity decrease in heart rate, and thus prone to undesirable bradycardia, the symptoms were significantly more frequent and more strongly expressed in patients who are poor metabolisers. In addition, metoprolol in high concentrations in plasma may lose cardioselectivity, exposing the PM patients to side effects characteristic of non-selective $\beta$-blockers, such as the bronchospasm [16].

The relationship between CYP2D6 genotype and the occurrence of adverse effects from metoprolol was the subject of study by Wuttke et al. [17]. They found a statistically significant approximately 5 -fold increased risk of adverse reactions (either $\beta$-blocker specific, for example, symptomatic bradycardia, or non-specific, for example nausea) in PMs $(p<0.0001)$. The study included 24 patients, while 9 patients were slow metabolisers. In our study, adverse event rates were not influenced by differences in plasma concentration of metoprolol and the CYP2D6 genotypes.

In our study, the concentration of metoprolol was determined by using the new and unique HPLC method in the author's own modification with a Corona CAD detector (Charged Aerosol Detection). This method has satisfactorily parameters that guarantee repeatability and precision of results. The presented method of determining metoprolol by means of a Corona CAD detector may be a good alternative for well known in literature methods based on fluorescent detection.

In conclusion, the present study indicates that the plasma concentrations of metoprolol depends on the polymorphism of CYP2D6. Genetically determined differences in the oxidation may thus affect the efficacy and safety of treatment with metoprolol. This knowledge should be considered in clinical practice.

\section{Conflict of interest}

The authors have no conflicts of interest to declare.

\section{Funding}

The study was financed from the Medical University of Lodz, Poland (grant No. 503/8-011-01/503-01).

\section{References}

[1] Fox K, Garcia MA, Ardissino D, Buszman P, Camici PG, Crea F, et al. CPG guidelines on the management of stable angina pectoris: executive summary: the Task Force on the Management of Stable Angina Pectoris of the European Society of Cardiology. Eur Heart J 2006;27:1341-81.

[2] Rau T, Heide R, Bergmann K, Wuttke H, Werner U, Feifel N, et al. Effect of the CYP2D6 genotype on metoprolol metabolizm persists during long-term treatment. Pharmacogenetics 2002;12:465-72.

[3] Classen DC, Pestotnik SL, Evans RS, Lloyd JF, Burke JP. Adverse drug events in hospitalized patients. Excess length of stay, extra costs, and attributable mortality. JAMA 1997;277:301-6.

[4] Lazarou J, Pomeranz BH, Corey PN. Incidence of adverse drug reactions in hospitalized patients: a metaanalysis of prospective studies. JAMA 1998;279:1200-5.

[5] Wojtczak A, Rychlik-Sych M, Krochmalska-Ulacha E, Skretkowicz J. CYP2D6 phenotyping with dextromethorphan. Pharmacol Rep 2007;59(6):734-8.

[6] Wojtczak A, Skrętkowicz J. Clinical significance of some genetic polymorphisms of cytochrome P-450 subfamilies CYP2D, CYP2E and CYP3A - part II. Pol Merkur Lekarski 2009;27(158):166-9.

[7] Zhou S. Polymorphism of human cytochrome P450 2D6 and its clinical significance: part I. Clin Pharmacokinet 2009;48(11):689-723.

[8] Smith CA, Gough AC, Leigh PN, Summers BA, Harding AE, Maraganore DM, et al. Debrisoquine hydroxylase gene polymorphisms and susceptibility to Parkinson's disease. Lancet 1992;6:1375-7.

[9] Zhou HH, Wood AJ. Stereoselective disposition of carvedilol is determined by CYP2D6. Clin Pharmacol Ther 1995:57:518-24.

[10] Kirchheiner J, Heesch C, Bauer S, Meisel C, Seringer A, Goldammer M, et al. Impact of the ultrarapid metabolizer genotype of cytochrome P450 2D6 on metoprolol pharmacokinetics and pharmacodynamics. Clin Pharmacol The 2004;76:302-12.

[11] Koytchev R, Alken RG, Vlahov V, Kirkov V, Kaneva R, Thyroff-Friesinger U, et al. Influence of the cytochrome P4502D6*4 allele on the pharmacokinetics of controlled-release metoprolol. Eur J Clin Pharmacol 1998;54:469-74.

[12] Taguchi M, Nozawa T, Mizumaki K, Inoue H, Tahara K, Takesono C, et al Nonlinear mixed effects model analysis of the pharmacokinetics of metoprolol in routinely treated Japanese patients. Biol Pharm Bull 2004;27:1642-8.

[13] Nozawa T, Taguchi M, Tahara K, Hashimoto Y, Igarashi N, Nonomura M, et al Influence of CYP2D6 genotype on metoprolol plasma concentration and $\beta$ adrenergic inhibition during long-term treatment: a comparison with bisoprolol. J Cardiovasc Pharmacol 2005;46:713-20.

[14] Blake CM, Kharasch ED, Schwab M, Nagele P. A meta-analysis of CYP2D6 metabolizer phenotype and metoprolol pharmacokinetics. Clin Pharmacol Ther 2013:94(3):394-9.

[15] Sharp CF, Gardiner SJ, Jensen BP, Roberts RL, Troughton RW, Lainchbury JG et al. CYP2D genotype and its relationship with metoprolol dose, concentrations and effect in patients with systolic heart failure. Pharmacogenomics J 2009:9:175-84

[16] Lennard MS, Silas JH, Freestone S, Ramsay LE, Tucker GT, Woods HF. Oxidation phenotype - a major determinant of metoprolol metabolism and response. $\mathrm{N}$ Engl J Med 1982;307:1558-60.

[17] Wuttke H, Rau T, Heide R, Bergmann K, Böhm M, Weil J, et al. Increased frequency of cytochrome P450 2D6 poor metabolizers among patients with metoprolol-associated adverse effects. Clin Pharmacol Ther 2002;72:429-37. 